\title{
Multi Scale Modeling and Failure Analysis of Laminated Composites
}

\section{Uniyal $P^{*}$, Gunwant D and Misra A}

Department of Mechanical Engineering, Gbpuat Pantnagar, India

\begin{abstract}
In present study a multi scale modeling and failure analysis of laminated composites is performed. for micro level study Rule of Mixtures and Halphin-Tsai equations are used to determine lamina properties. Off-axis failure strength of lamina for different volume fractions are calculated using Finite Element software ANSYS. Finite element analysis results are compared with analytical results and published experimental results. In macro level study of laminates first ply failure load of laminates is calculated using ANSYS and compared with analytical results. Various failure theories i.e. maximum stress theory, maximum strain theory, Tsai-Wu, Tsai-Hill and Puck failure criteria are implemented. First ply failure load for different lamination schemes are calculated for uni-axial and Bi-axial loading conditions.
\end{abstract}

Keywords: Composites; Macromechanical analysis

\section{Introduction}

Laminated composites are made by stacking various layers of unidirectional lamina at different angles to provide required stiffness and strength in particular direction. Each lamina is made up of unidirectional fibers arranged in a matrix. Hence study of laminated composites can be performed at different scales. In micromechanical analysis of lamina properties of individual constituents, interaction between fiber and matrix, distribution of fibers in matrix all these factors are considered. In macromechanical analysis lamina is considered as a homogenous and orthotropic body. In macromechanical analysis of laminates entire stack of lamina is considered as a single body and integration of individual properties of lamina are used for analysis. Micromechanics of lamina is helpful while developing new fiber matrix system. Macro level analysis of lamina can be used when determine stress and strains in lamina. Further off axis strengths can be calculated when loading is not along the direction of fibers. Macromechanical analysis of laminates is capable to predict behavior of laminates under different loading conditions.

Experimental study of laminated composites is expensive and time consuming work. Hence so many theoretical models have been proposed to determine properties of laminated composites. For micromechanical analysis of lamina Halphin and Tsai proposed model to predict elastic properties of lamina. Huang developed a formulae based on micromechanics to predict strength properties of lamina [1]. Off-axis strength of lamina is important when direction of loading is not along the direction of fibers. Pipes performed a benchmark experimental study on boron-epoxy, aramid-epoxy and graphite epoxy lamina to determine off-axis failure strength [2]. First ply failure load is important parameter while designing laminated composite structure. Theoretical and finite element analysis procedures have been developed to determine first ply failure of laminated composites. Reddy et al. performed a benchmark study to determine first ply failure load of laminated composites using finite element method [3]. Kam et al. determined first ply failure load of laminated composites using analytical and experimental methods [4]. Rahimi et al. determined first ply failure and last ply failure loads for $\left[\Theta_{4} / 0_{4} /-\Theta_{4}\right]_{s}$ lamination scheme using finite element software ANSYS [5,6].
In present work modeling and failure analysis of laminated composites is performed using finite element software ANSYS. Finite element results are compared with theoretical results. Theoretical procedure is coded in MATLAB program.

\section{Methodology}

In present study investigation is carried out at three different scales. In micromechanics of lamina Rule of Mixtures and Halphin-Tsai equations are used for to determine elastic properties of lamina. Haug's micromechanics approach is used to determine strength properties of lamina. For macromechanics of lamina generalized Hook's law is used to determine stress and strains in local axis and various failure theories are used to determine failure strength. For macromechanical analysis of laminates ANSYS software is used to determine first ply failure load. Various failure theories are coded in MATLAB to determine first ply failure load of laminates.

\section{Micromechanics of lamina}

In present investigation semi-empirical method Halphin-Tsai model is used to determine elastic properties of lamina. Halphin-Tsai proposed following relations to determine elastic properties of lamina-

\section{Longitudinal Young's Modulus-}

$$
E_{1}=E_{f} V_{f}+E_{m} V_{m}
$$

\section{Transverse Young's Modulus-}

$$
\begin{aligned}
& E_{2}=\frac{1+\xi \eta V_{f}}{1-\eta V_{f}} E_{m} \\
& \eta=\frac{\left(E_{f} / E_{m}\right)-1}{\left(E_{f} / E_{m}\right)+\xi}
\end{aligned}
$$

*Corresponding author: Uniyal P, Department of Mechanical Engineering, Gbpuat Pantnagar, India, Tel: 05944233 320; E-mail: piyu.uniyal@gmail.com

Received June 22, 2016; Accepted August 19, 2016; Published August 24, 2016

Citation: Uniyal P, Gunwant D, Misra A (2016) Multi Scale Modeling and Failure Analysis of Laminated Composites. J Appl Mech Eng 5: 229. doi: 10.4172/21689873.1000229

Copyright: (C) 2016 Uniyal P, et al. This is an open-access article distributed under the terms of the Creative Commons Attribution License, which permits unrestricted use, distribution, and reproduction in any medium, provided the original author and source are credited. 
In plane Poisson's Ratio-

$v_{12}=v_{f} V_{f}+v_{m} V_{m}$

In plane Shear Modulus-

$$
\begin{aligned}
& G_{12}=\frac{1+\xi \eta V_{f}}{1-\eta V_{f}} G_{m} \\
& \eta=\frac{\left(G_{f} / G_{m}\right)-1}{\left(G_{f} / G_{m}\right)+\xi} \\
& \xi=1+40 V_{f}^{10}
\end{aligned}
$$

\section{Macromechanics of lamina}

Hook's law for 2-D Lamina: Laminates are generally made up of stacking various layers at different angles because lamina is weak in the direction perpendicular to fibers. Hence to provide transverse stiffness and strength lamina are placed at various angles. So it is necessary to develop a stress-strain relationship for an angle lamina.

For an angle lamina it required to define a different co-ordinate system which is known as local co-ordinate system. Axis along the direction of fibers is known as longitudinal local axis whereas axis perpendicular to the fiber is known as transverse local axis.

The hook's law for a 2D angle lamina can be written as:

$$
\left[\begin{array}{c}
\sigma_{x} \\
\sigma_{y} \\
\tau_{x y}
\end{array}\right]=[T]^{-1}[Q][R][T][R]^{-1}\left[\begin{array}{c}
\varepsilon_{x} \\
\varepsilon_{y} \\
\varepsilon_{x y}
\end{array}\right]
$$

Where,

$$
[T]=\left[\begin{array}{ccc}
c^{2} & s^{2} & 2 s c \\
s^{2} & c^{2} & -2 s c \\
-s c & s c & c^{2}-s^{2}
\end{array}\right], c=\cos (\theta) \text { and } s=\sin (\theta)
$$$$
[Q]=\text { Stiffness matrix }
$$$$
[R]=\left[\begin{array}{lll}
1 & 0 & 0 \\
0 & 1 & 0 \\
0 & 0 & 2
\end{array}\right] \text {,Reuter's matrix }
$$

Above equation can be written as-

$$
\begin{aligned}
& {\left[\begin{array}{c}
\sigma_{x} \\
\sigma_{y} \\
\tau_{x y}
\end{array}\right]=\left[\begin{array}{lll}
Q_{11}^{-} & Q_{12}^{-} & Q_{16}^{-} \\
Q_{12}^{-} & Q_{22}^{-} & Q_{26}^{-} \\
Q_{16}^{-} & Q_{26}^{-} & Q_{66}^{-}
\end{array}\right]\left[\begin{array}{c}
\varepsilon_{x} \\
\varepsilon_{y} \\
\varepsilon_{x y}
\end{array}\right]} \\
& \text { Or }\left[\begin{array}{c}
\varepsilon_{x} \\
\varepsilon_{y} \\
\varepsilon_{x y}
\end{array}\right]=\left[\begin{array}{lll}
S_{11}^{-} & S_{12}^{-} & S_{16}^{-} \\
S_{12}^{-} & S_{22}^{-} & S_{26}^{-} \\
S_{16}^{-} & S_{26}^{-} & S_{66}^{-}
\end{array}\right]\left[\begin{array}{l}
\sigma_{x} \\
\sigma_{y} \\
\tau_{x y}
\end{array}\right]
\end{aligned}
$$

Where,

$\left[\mathrm{Q}^{-}\right]=$Reduced Stiffness matrix.

$\left[\mathrm{S}^{-}\right]=$Reduced Compliance matrix (inverse of reduced striffness matrix).

\section{Failure Theories}

\section{Maximum stress failure theory}

This theory is based on maximum stress theory of Rankine and maximum shear stress theory of Tresca. According to this theory failure occurs when any one of stress in material axis exceeded the failure value of stress.

Lamina is considered to be failed if any one of the following conditions violates-

$$
\begin{aligned}
& -\left(\sigma_{1}^{C}\right)_{u l t}<\left(\sigma_{1}\right)<\left(\sigma_{1}^{T}\right)_{u l t} \\
& -\left(\sigma_{2}^{C}\right)_{u l t}<\left(\sigma_{2}\right)<\left(\sigma_{2}^{T}\right)_{u l t} \\
& -\left(\tau_{12}\right)_{u l t}<\tau_{12}<\left(\tau_{12}\right)_{u l t}
\end{aligned}
$$

\section{Maximum strain failure theory}

This theory is based on max. Strain theory of St. Venant. According to this theory lamina fails when values of strains in material axis exceed limiting values of strains.

Lamina is considered to be failed if any one of the following conditions violates-

$$
\begin{aligned}
& -\left(\varepsilon_{1}^{C}\right)_{u l t}<\left(\varepsilon_{1}\right)<\left(\varepsilon_{1}^{T}\right)_{u l t} \\
& -\left(\varepsilon_{2}^{C}\right)_{u l t}<\left(\varepsilon_{2}\right)<\left(\varepsilon_{2}^{T}\right)_{u l t} \\
& -\left(\gamma_{12}\right)_{u l t}<\gamma_{12}<\left(\gamma_{12}\right)_{u l t}
\end{aligned}
$$

\section{Tsai-Wu failure theory}

This interactive failure theory is based on strain energy theory for isotropic materials.

Tsai-Wu failure theory when applied to a lamina states that, a lamina is considered to be safe if:

$$
\begin{aligned}
& H_{1} \sigma_{1}+H_{2} \sigma_{2}+H_{6} \tau_{12}+H_{11} \sigma_{2}^{2}+H_{66} \tau_{12}^{2}+2 H_{12} \sigma_{1} \sigma_{2}<1 \\
& H_{2}=\frac{1}{\left(\sigma_{1}^{T}\right)_{u l t}}-\frac{1}{\left(\sigma_{1}^{C}\right)_{u l t}}, \\
& H_{11}=\frac{1}{\left(\sigma_{1}^{T}\right)_{u l t}\left(\sigma_{1}^{C}\right)_{u l t}} \\
& H_{2}=\frac{1}{\left(\sigma_{2}^{T}\right)_{u l t}}-\frac{1}{\left(\sigma_{2}^{C}\right)_{u l t}}, \\
& H_{22}=\frac{1}{\left(\sigma_{2}^{T}\right)_{u l t}\left(\sigma_{2}^{C}\right)_{u l t}} \\
& H_{6}=0, H_{66}=\frac{1}{\left(\tau_{12}\right)_{u l t}^{2}} \\
& { }_{12}=-\frac{)_{u l t}}{2(}, \text { as per Tsai }- \text { Hill failure theory }
\end{aligned}
$$




$$
\begin{aligned}
& H_{12}=-\frac{1}{2 \sigma_{1 u l t}^{T} \sigma_{1 u l t}^{C}} \text {, as per Hoffman criterion } \\
& H_{12}=-\frac{1}{2} \sqrt{\frac{1}{\left(\sigma_{1}^{T}\right)_{u l t}\left(\sigma_{1}^{C}\right)_{u l t}\left(\sigma_{2}^{T}\right)_{u l t}\left(\sigma_{2}^{C}\right)_{u l t}}} \text { as per Mises - Hencky criterion }
\end{aligned}
$$

\section{Tsai-Hill failure theory}

Based on distortion energy theory for isotropic materials. Lamina is considered fail when following condition violates-

$$
\begin{aligned}
& \left(G_{2}+G_{3}\right) \sigma_{1}^{2}+\left(G_{1}+G_{3}\right) \sigma_{2}^{2}+\left(G_{1}+G_{2}\right) \sigma_{3}^{2}-2 G_{3} \sigma_{1} \sigma_{2}-2 G_{2} \sigma_{1} \sigma_{3}-2 G_{1} \sigma_{3} \sigma_{2}+2 G_{4} \tau_{23}^{2}+2 G_{5} \tau_{13}^{2}+2 G_{6} \tau_{12}^{2}<1 \\
& G_{1}=\frac{1}{2}\left(\frac{2}{\left[\left(\sigma_{2}^{T}\right)_{u l t}\right]^{2}}-\frac{1}{\left[\left(\sigma_{1}^{T}\right)_{u l t}\right]^{2}}\right) \\
& G_{2}=G_{3}=\frac{1}{2}\left(\frac{1}{\left[\left(\sigma_{1}^{T}\right)_{u l t}\right]^{2}}\right) \\
& G_{6}=\frac{1}{2}\left(\frac{1}{\left[\left(\tau_{12}\right)_{u l t}\right]^{2}}\right)
\end{aligned}
$$

\section{Modeling and Finite Element Analysis of Laminates in} ANSYS

\section{Steps involve in finite element analysis (ANSYS)}

Finite element analysis involves three stages of activity: preprocessing, processing and post processing. A complete finite element analysis is a logical interaction of the three stages.

Steps of finite element analysis in ANSYS-

- Preprocessing

- Specify element types to be used

- Specify options for element behavior

- Specify real constants

- Specify material model
- Specify material properties

- Create geometry

- Specify meshing options

- Mesh model

- Apply boundary conditions

- Solve problem

- Post processing (reviewing results)

\section{Material properties}

Shown in Tables 1-4.

\section{Results and Discussion}

\section{Micromechanical analysis of lamina}

In this section three different fibers Graphite, Boron and Aramid fibers with epoxy as a matrix system has been analyzed. Elastic properties such as Young's modulus, Poission'ratio, shear modulus and strength properties has been calculated and compared at different fiber volume fractions. Volume fraction of fibers is varied from $30 \%$ to $65 \%$.

Figure 1 shows a linear variation of longitudinal Young's modulus with fiber volume fraction. Boron/epoxy composition shows maximum value of longitudinal and transverse Young's modulus, and longitudinal tensile strength among aramid/epoxy and graphite/epoxy compositions whereas aramid/epoxy exhibits minimum values among all compositions. Transverse Young's modulus shows a nonlinear trend with fiber volume fraction. It can be observed that up to 0.4 volume fraction there is no significant difference in transverse Young's modulus for three different fiber and values are diverging as volume fraction increases. Stiffness and strength of lamina increases with increase in number of fibers.

\section{Macromechanical analysis of lamina}

In this section strength of lamina is calculated when orientation of fibers is not along the direction of loading. This strength is also known as off-axis strength of lamina. Off axis strength of lamina is calculated using FEA software ANSYS and stress-strain relationship and failure theory are

\begin{tabular}{|c|c|c|c|c|c|c|c|}
\hline & $\mathbf{E}_{\mathbf{1}}(\mathbf{G P a})$ & $\mathbf{E}_{\mathbf{2}}(\mathbf{G P a})$ & $v_{12}$ & $v_{23}$ & $\mathbf{G}_{\mathbf{1 2}}(\mathbf{G P a})$ & $\mathbf{X}_{\mathbf{t}}(\mathbf{M P a})$ & $\mathbf{Y}_{\mathbf{t}}(\mathbf{M P a})$ \\
\hline Graphite & 213.7 & 13.8 & 0.2 & 0.25 & 13.8 & 2250 \\
\hline Epoxy & 3.45 & 3.45 & 0.35 & 0.35 & 1.3 & - \\
\hline
\end{tabular}

Table 1: Properties of graphite and epoxy [15].

\begin{tabular}{|c|c|c|c|c|c|c|c|}
\hline & $\mathbf{E}_{\mathbf{1}}(\mathbf{G P a})$ & $\mathbf{E}_{\mathbf{2}}(\mathbf{G P a})$ & $v_{12}$ & $v_{23}$ & $\mathbf{G}_{12}(\mathbf{G P a})$ & $\mathbf{X}_{\mathbf{t}}(\mathbf{M P a})$ & $\mathbf{Y}_{\mathbf{t}}(\mathbf{M P a})$ \\
\hline Boron & 400 & & 0.2 & & 166.7 & 2566 \\
\hline Epoxy & 3.45 & 3.45 & 0.35 & 0.35 & 1.3 & - \\
\hline
\end{tabular}

Table 2: Properties of boron and epoxy [15].

\begin{tabular}{|c|c|c|c|c|c|c|c|}
\hline & $\mathbf{E}_{\mathbf{1}}(\mathbf{G P a})$ & $\mathbf{E}_{\mathbf{2}}(\mathbf{G P a})$ & $v_{12}$ & $v_{23}$ & $\mathbf{G}_{12}(\mathbf{G P a})$ & $\mathbf{X}_{\mathbf{t}}(\mathbf{M P a})$ & $\mathbf{Y}_{\mathbf{t}}(\mathbf{M P a})$ \\
\hline Aramid & 124.1 & 4.1 & 0.35 & 0.35 & 2.9 & 2031 \\
\hline Epoxy & 3.45 & 3.45 & 0.35 & 0.35 & 1.3 & - \\
\hline
\end{tabular}

Table 3: Properties of aramid and epoxy [15].

\begin{tabular}{|c|c|c|c|c|c|c|c|}
\hline $\mathbf{E}_{\mathbf{X}}(\mathbf{G P a})$ & $\mathbf{E}_{\mathbf{Y}}(\mathbf{G P a})$ & $v_{x y}$ & $\mathbf{G}_{\mathbf{x y}}(\mathbf{G P a})$ & $\mathbf{X}_{\mathbf{t}}(\mathbf{M P a})$ & $\mathbf{X}_{\mathrm{c}}(\mathbf{M P a}$ & $\mathbf{Y}_{\mathbf{t}}(\mathbf{M P a})$ & $\mathbf{Y}_{\mathrm{c}}(\mathbf{M P a})$ \\
\hline 204 & 185 & 0.23 & 5.59 & 1260 & 2500 & 61 \\
\hline
\end{tabular}

Table 4: Elastic and strength properties for boron-epoxy lamina [15]. 


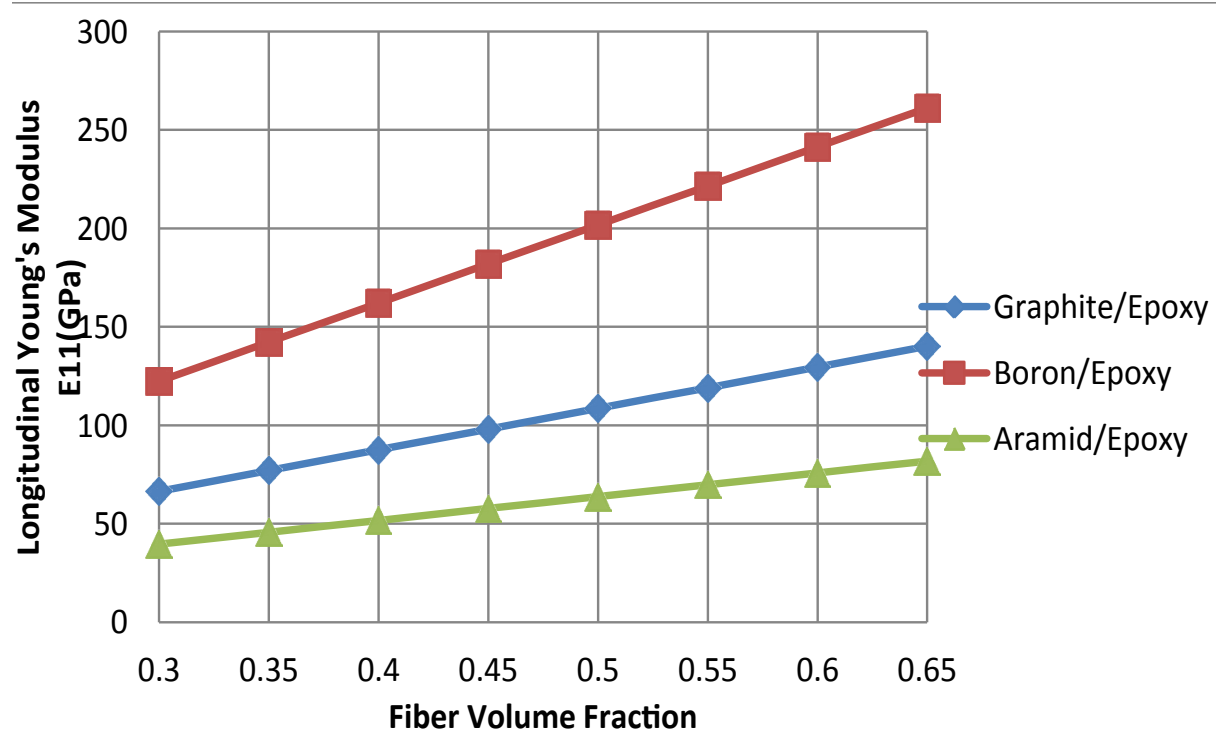

Figure 1: Variation of longitudinal Young's modulus with fiber volume fraction.

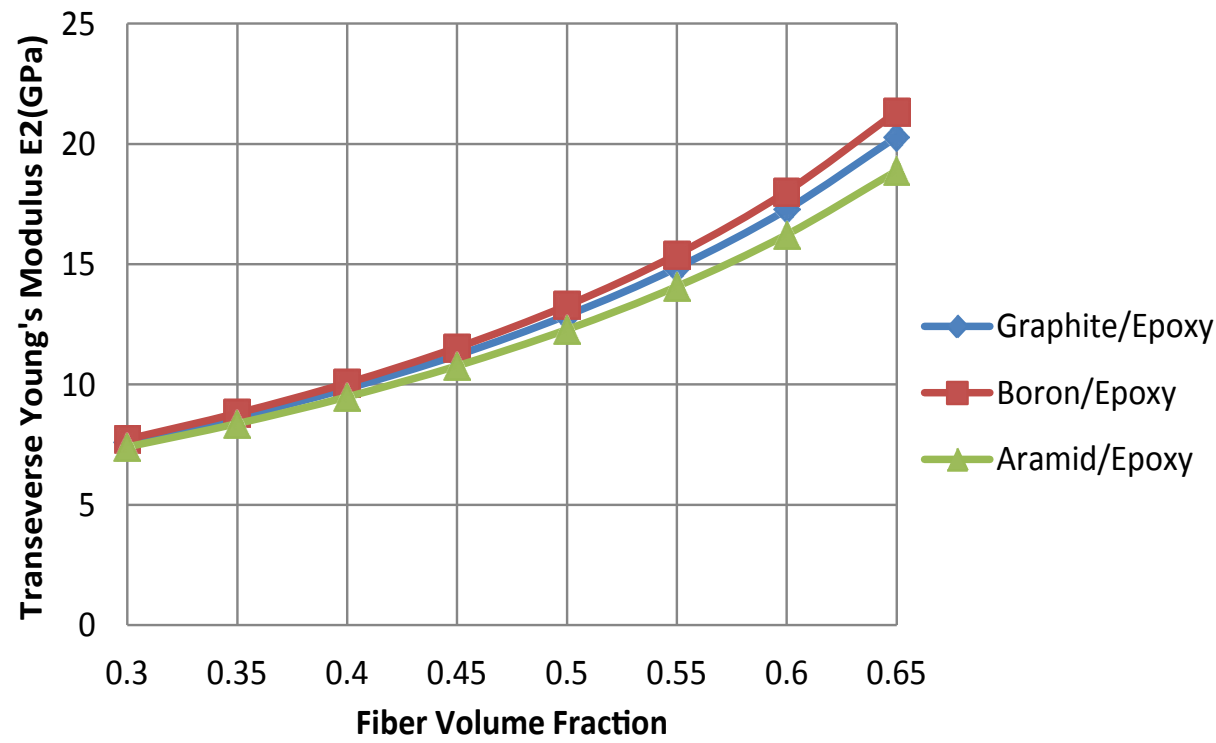

Figure 2: Variation of transverse young's modulus with fiber volume fraction.

\begin{tabular}{|c|c|c|}
\hline \multirow{2}{*}{ Fiber Orientation Angle } & \multicolumn{2}{|c|}{ Off-axis Failure Strength (MPa) } \\
\cline { 2 - 3 } & FEM(ANSYS) & Experimental [14] \\
\hline $15^{\circ}$ & 217.68 & 231.28 \\
\hline $30^{\circ}$ & 113.07 & 123.16 \\
\hline $45^{\circ}$ & 79.64 & 84.87 \\
\hline $60^{\circ}$ & 64.72 & 63.94 \\
\hline
\end{tabular}

Table 5: Comparison of FEM results with experimental results [14].

coded in MATLAB. Results obtained using ANSYS and MATLAB are compared with available experimental results. Finally variation of off-axis strength with fiber orientation angle is plotted for different volume fraction of boron fiber in epoxy matrix (Figures 2 and 3 ).

\section{Validation of FEA model (ANSYS)}

Comparison of FEM results with Experimental Results [7] shown in Table 5 . 


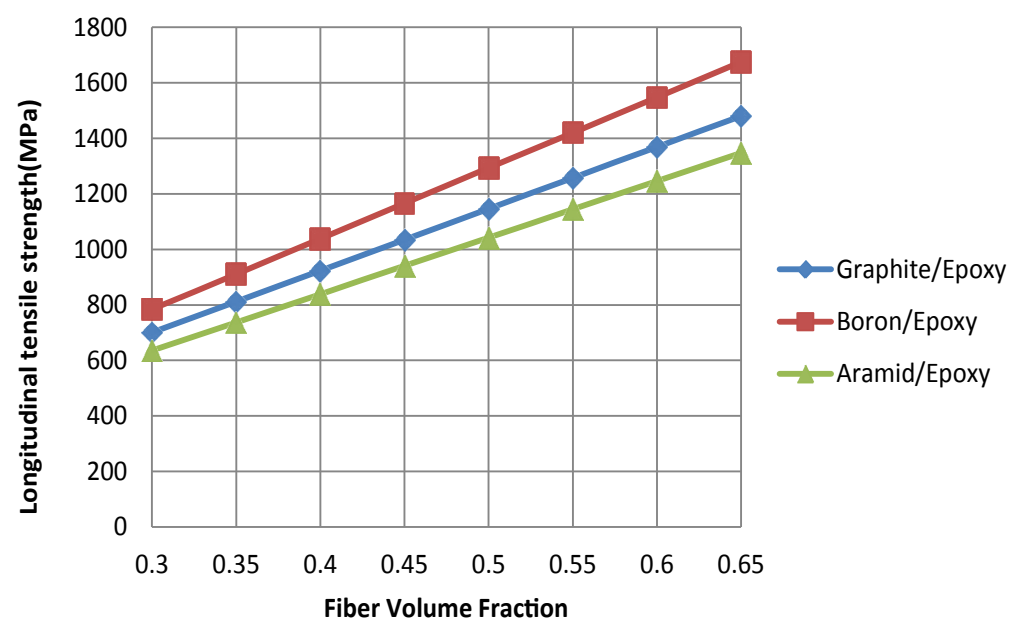

Figure 3: Variation of longitudinal tensile strength with fiber volume fraction.

Variation in Failure Stress with fiber orientation angle

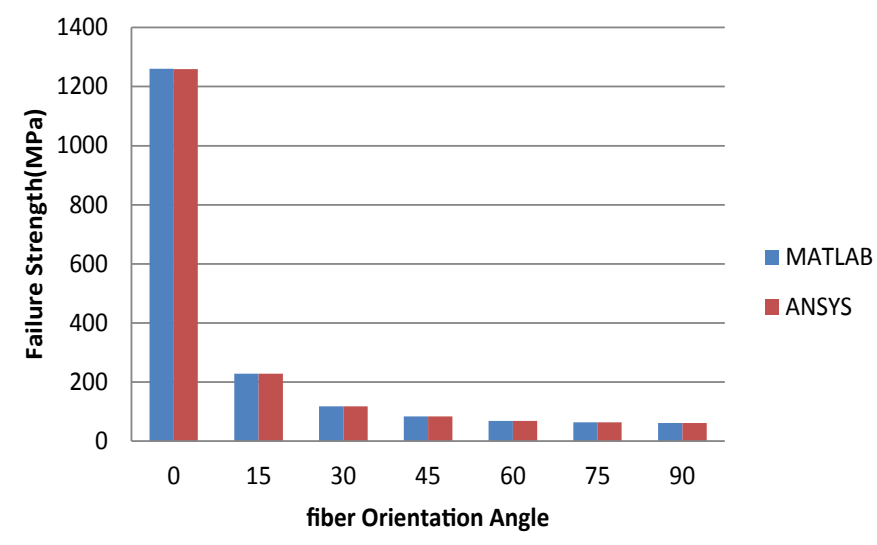

Figure 4: Comparison of ANSYS results with theoretical results.

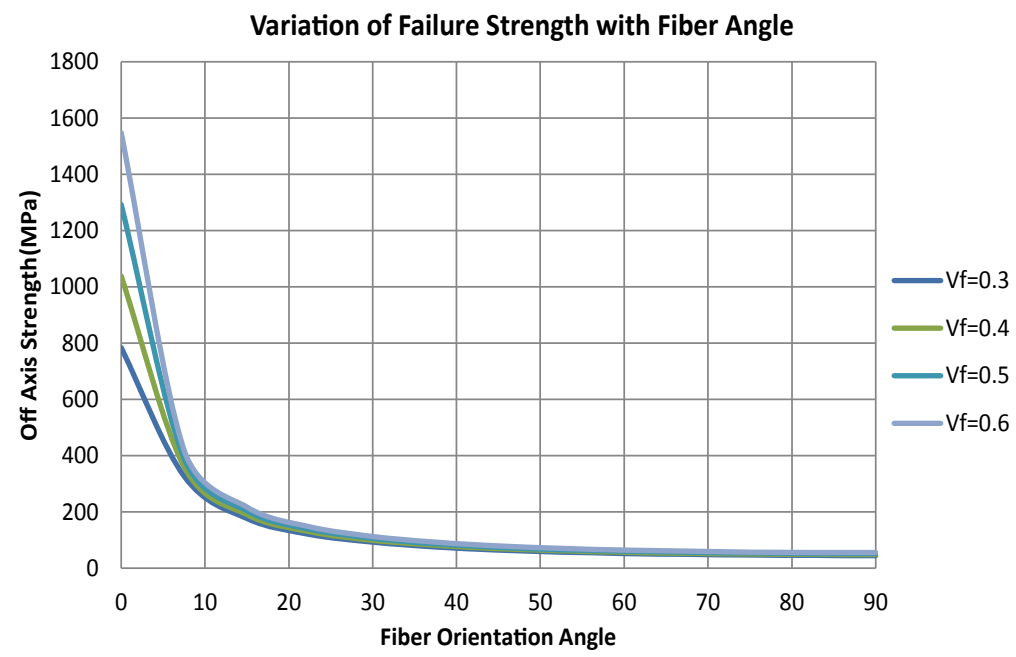

Figure 5: Variation of off axis failure strength with fiber orientation for different volume fractions. 
Citation: Uniyal P, Gunwant D, Misra A (2016) Multi Scale Modeling and Failure Analysis of Laminated Composites. J Appl Mech Eng 5: 229. doi: 10.4172/2168-9873.1000229

Page 6 of 10

In Figure 4 comparison between FEA (ANSYS) results and theoretical (MATLAB) results is presented. A very good agreement is found between ANSYS and MATLAB results. Failure strength at different fiber orientation angles and local stress results are calculated using ANSYS and MATLAB. From above observations it can be concluded that analysis of lamina can be performed accurately using ANSYS.

\section{Variation of off-axis strength with fiber orientation angle for different volume fractions}

It has been observed from Figure 5 that failure strength decreases with increase in fiber orientation angle. Maximum strength is obtained when loading is along the direction of fibers and minimum when loading is perpendicular to the direction of fibers. Higher strength values are associated with higher fiber volume fractions. It is also noticeable that effect of fiber volume fraction is only significant for only low fiber orientation angles. Beyond $10^{\circ}$ fiber orientation angles failure strength of lamina is almost same for all volume fractions. Since cost is directly associated with fiber volume fractions. Higher the fiber volume fraction, higher will be cost of lamina. Hence it is suggested to use lamina with lower fiber volume fraction when off axis angles are higher than $10^{\circ}$.

\section{Macro-mechanical Analysis of Laminates}

\section{Validation of FEA (ANSYS) model}

Comparison of FEA (ANSYS) results with Experimental data [8] for $\left(0_{2} / 90_{2}\right)_{s}$ laminate shown in Table 6 .

Comparison of FEA (ANSYS) results with Experimental data [8] for $\left(0^{\circ} / 90^{\circ} / 0^{\circ} / 90^{\circ}\right)$ s laminate shown in Table 7 .

\section{Uniaxial loading}

Case 1: $(0 \% \mathbf{\Theta} / \mathbf{0} \boldsymbol{\Theta} / \boldsymbol{\Theta} \mathbf{\Theta})$ : Shown in Table 8. From Figure 6 it can be concluded that failure strength is maximum when all layers are orientated at $0^{\circ}$ and minimum for $(0 \% 90 \%$ ) laminates. First ply failure strength decreases as $\Theta$ increases for $(0 \% \Theta \%$ ) laminates.
Failure strength drastically decreases from $0^{\circ}$ to $15^{\circ}$ which is from $1260 \mathrm{MPa}$ to $760.75 \mathrm{MPa}$ according to maximum stress theory. Results obtained using Tsai-Wu and Puck failure criteria are very close whereas maximum stress theory predicts higher failure load in range of $15^{\circ}$ to $60^{\circ}$.

Case 2: $\left(\boldsymbol{\theta}^{\circ} / 90^{\circ}-\boldsymbol{\theta}^{\circ} / \boldsymbol{\theta}^{\circ} / 90^{\circ}-\boldsymbol{\theta}^{)}\right)$s: For $\left(\Theta^{\circ} / 90^{\circ}-\Theta^{\circ} / \Theta^{\circ} / 90^{\circ}-\Theta^{\circ}\right)$ lamination scheme from Figure 7 it can be concluded that results for failure stress are symmetric about $\Theta=45^{\circ}$. Failure strengths predicted using different failure criteria are very close except maximum stress theory at $45^{\circ}$. Maximum stress theory predicts higher failure load at $45^{\circ}$ compare to other failure theories. $\left(45^{\circ} / 45^{\circ} / 45^{\circ} / 45\right)_{\text {s }}$ lamination scheme shows minimum failure strength as compare to other combinations [9-15].

Case 3: $\left(\boldsymbol{\theta}^{\circ} /-\boldsymbol{\theta} \% \mathbf{\theta} /-\boldsymbol{\theta}\right)$ s: Figure 8 shows variation of failure strength with layer orientation angle $\Theta$ for angle ply lamination scheme. It can be observed from figure that failure strength decreases drastically as ply angle from $15^{\circ}$ to $30^{\circ}$. Beyond $45^{\circ}$ curve become asymptotic to $\mathrm{X}$ axis and there is no significant variation in failure strength. All failure criteria provide almost same results. Maximum stress theory predicts higher failure loads compare to other failure theories (Figure 9).

Case 4: $\left(\boldsymbol{\Theta}^{\circ} / \mathbf{\theta}^{\circ} / \boldsymbol{\Theta}^{\circ} / \boldsymbol{\Theta}^{0}\right)$ s: Failure strength for unidirectional laminate is maximum when all layers are oriented along the direction of loading. For unidirectional laminates failure strength decreases drastically from $0^{\circ}$ to 15 . Beyond $15^{\circ}$ ply angles there is no significant difference in failure strength Results obtained using all failure criteria is very close (Figures 10-13).

\section{Biaxial loading}

Case 1: $(0 \% \boldsymbol{\Theta} \% \%$ ) s: Under bi-axial loading condition for $(0 \% \Theta$ $\% \Theta$ failure strength increases as $\Theta$ increases. Maximum failure strength is obtained when ply angle $\Theta$ is $90^{\circ}$. Failure strength increases rapidly beyond when ply angle $\Theta$ is greater than $60^{\circ}$. For lamination scheme $\left(0 \% \Theta^{\circ} \%\right.$ when $\Theta$ is $90^{\circ}$ laminate becomes cross ply laminate. Under bi axial loading cross ply laminates can take load in both directions. For unidirectional laminates under bi axial loading laminates is strong in longitudinal direction whereas weak in transverse direction.

\begin{tabular}{|c|c|c|c|}
\hline & Theoretical [3] & ANSYS & Experimental [3] \\
\hline Max. Stress & 229.11 & 225.63 & \\
\hline Max. Strain & 267.55 & & \\
\hline Tsai-Wu & 238.60 & 274.30 & \multirow{2}{*}{253.60} \\
\hline Tsai-Hill & 224.19 & & \\
\hline
\end{tabular}

Table 6: Comparison of FEA (ANSYS) results with experimental data [3] for $\left(\mathrm{O}_{2} / 90_{2}\right)_{\mathrm{s}}$ laminate.

\begin{tabular}{|c|c|c|c|}
\hline & Theoretical [3] & ANSYS & Experimental [3] \\
\hline Max. stress & 290.12 & 281.77 & \\
\hline Max. Strain & 355.47 & & \multirow{2}{*}{31.32} \\
\hline Tsai-Wu & 304.13 & 301.70 & \\
\hline Tsai-Hill & 280.81 & & \\
\hline
\end{tabular}

Table 7: Comparison of FEA (ANSYS) results with Experimental data [3] for $(0 \% 90 \% 0 \% 90)_{\mathrm{s}}$ laminate.

\begin{tabular}{|c|c|c|c|r|r|r|r|}
\hline \multirow{2}{*}{$\begin{array}{c}\text { Failure } \\
\text { Criteria }\end{array}$} & \multicolumn{4}{|c|}{ First Ply Failure Stress (MPa) } \\
\cline { 2 - 6 } & $0^{\circ}$ & $15^{\circ}$ & $30^{\circ}$ & $4^{\circ}$ & $7^{\circ}$ & 534.15 \\
\hline Max. Stress & 1260 & 760.75 & 778.07 & 714.20 & 413.57 \\
\hline Tsai-Wu & 1260 & 597.77 & 544.77 & 521.76 & 464.84 & 399.22 \\
\hline Tsai-Hill & 1260 & 675.67 & 610.37 & 565.66 & 485.20 & 403.89 \\
\hline Puck & 1260 & 666.67 & 588.23 & 526.31 & 476.19 & 400 \\
\hline Max Strain & 1260.5 & 758.58 & 778.29 & 737.65 & 538.77 & 413.19 \\
\hline
\end{tabular}

Table 8: Uniaxial loading. 
Citation: Uniyal P, Gunwant D, Misra A (2016) Multi Scale Modeling and Failure Analysis of Laminated Composites. J Appl Mech Eng 5: 229. doi: 10.4172/2168-9873.1000229

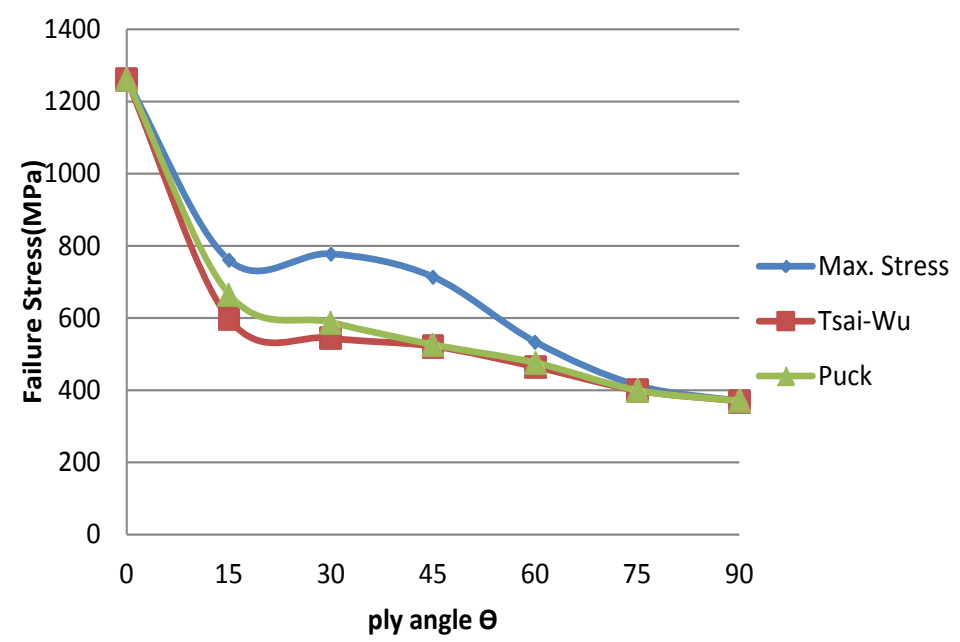

Figure 6: Variation of failure stress with ply angle $\Theta$ for $(0 \% \Theta \%$ ) laminate.

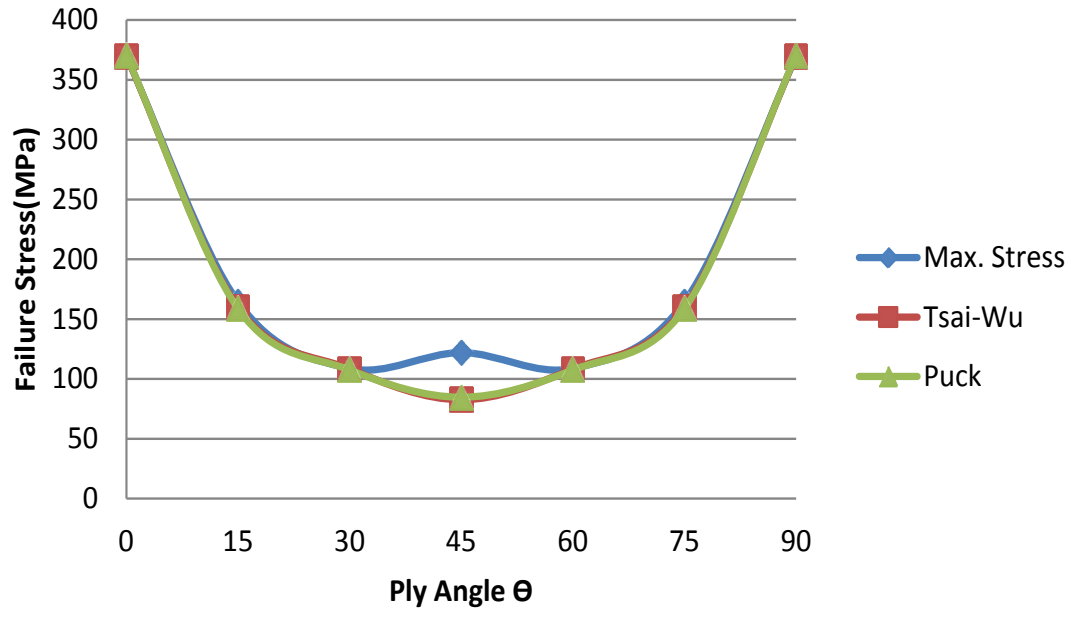

Figure 7: Variation of failure stress with ply angle $\theta$ for $\left(\theta^{\circ} / 90^{\circ}-\theta^{\circ} \theta^{\circ} / 90^{\circ}-\theta\right)$ laminate.

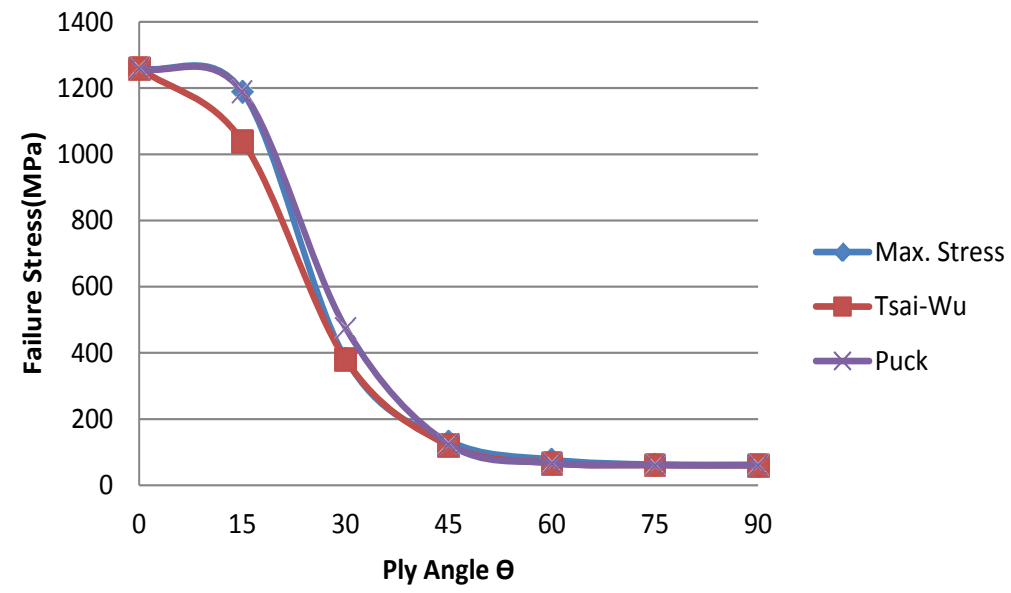

Figure 8: Variation of failure stress with ply angle $\theta$ for $(\theta \%-\theta \% \theta \%-\theta)$ laminate. 
Citation: Uniyal P, Gunwant D, Misra A (2016) Multi Scale Modeling and Failure Analysis of Laminated Composites. J Appl Mech Eng 5: 229. doi: 10.4172/2168-9873.1000229

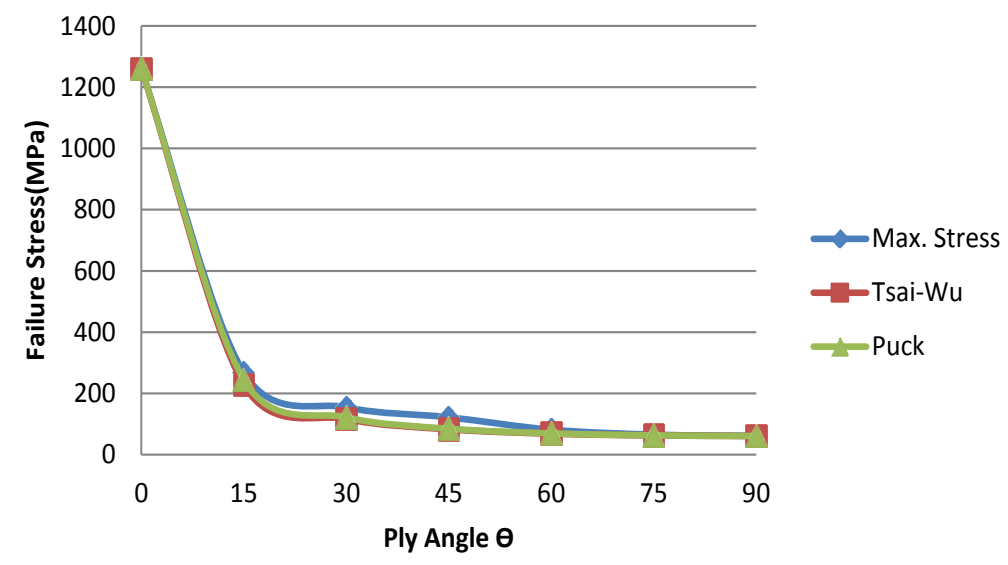

Figure 9: Variation of failure stress with ply angle $\theta$ for $(\theta \% \%$ $\theta \%)$ laminate.

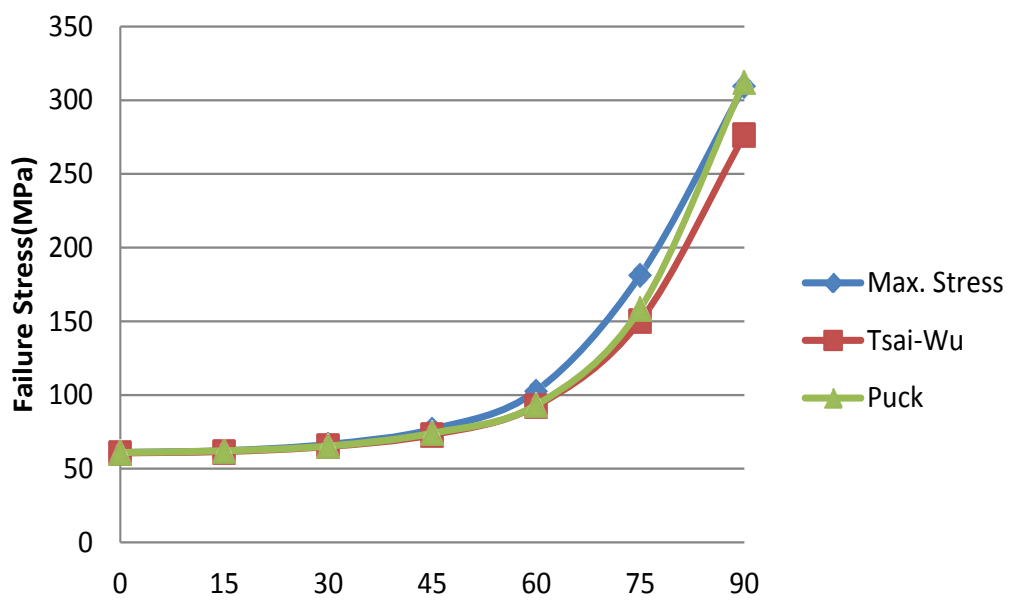

Ply Angle $\theta$

Figure 10: Variation of failure stress with ply angle $\theta$ for $(0 \% \% \%$ laminate

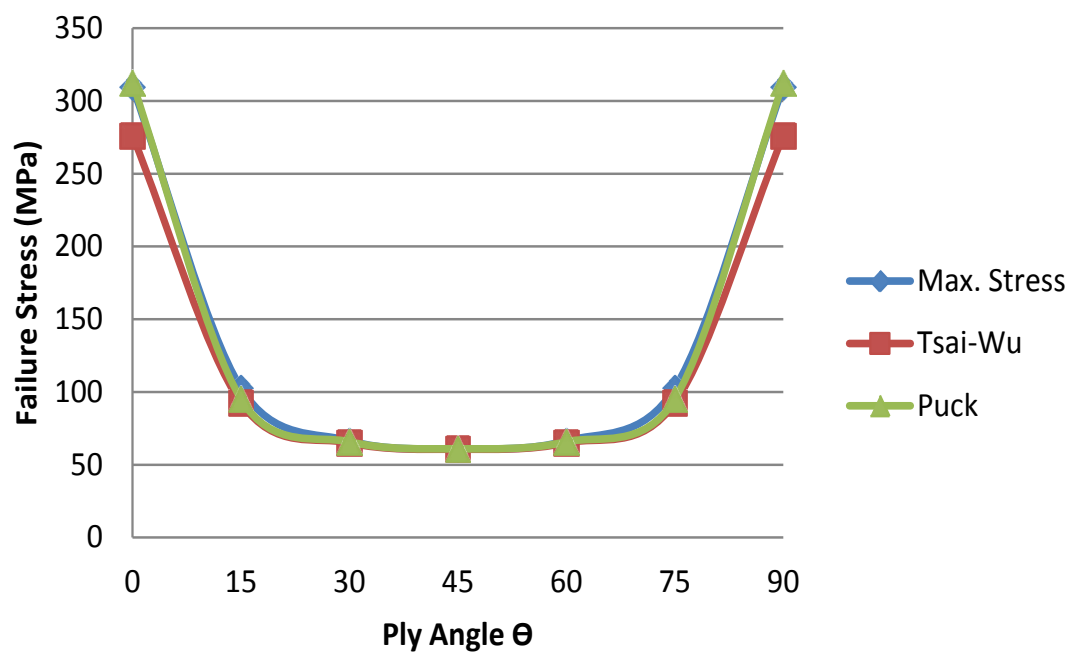

Figure 11: Variation of failure stress with ply angle $\theta$ for $\left(\theta^{\circ} / 90^{\circ}-\theta^{\circ} \theta^{\circ} / 90^{\circ}-\theta\right)$ laminate. 


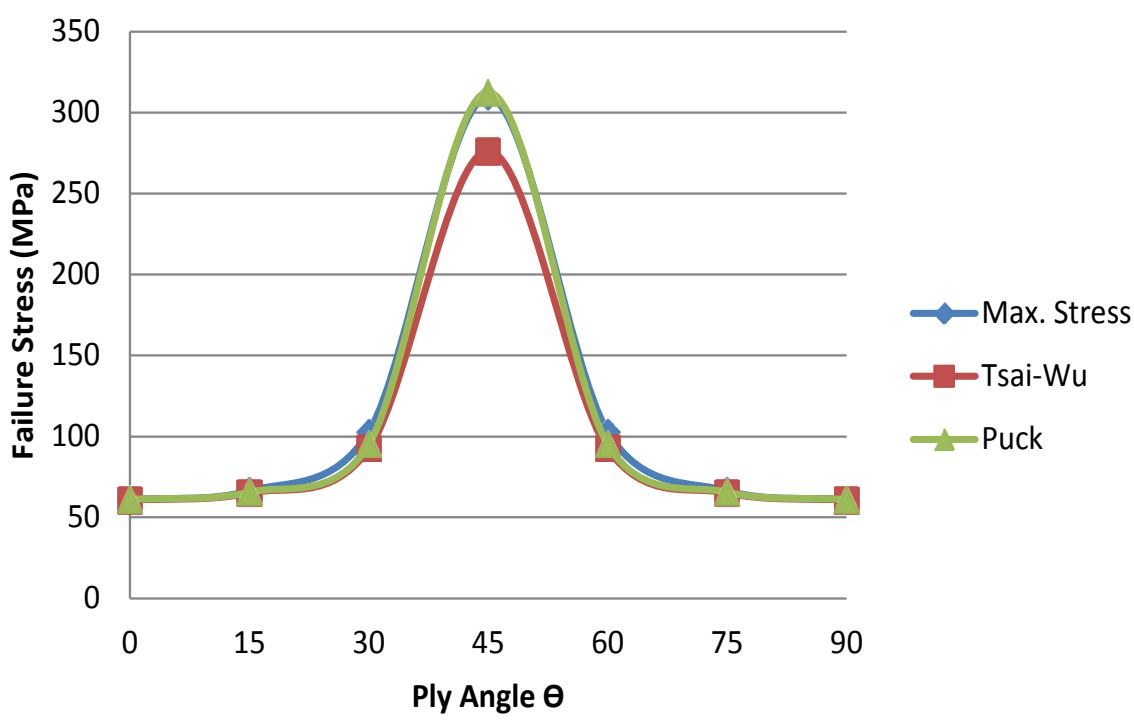

Figure 12: Variation of failure stress with ply angle $\theta$ for $(\theta \%-\theta \%$

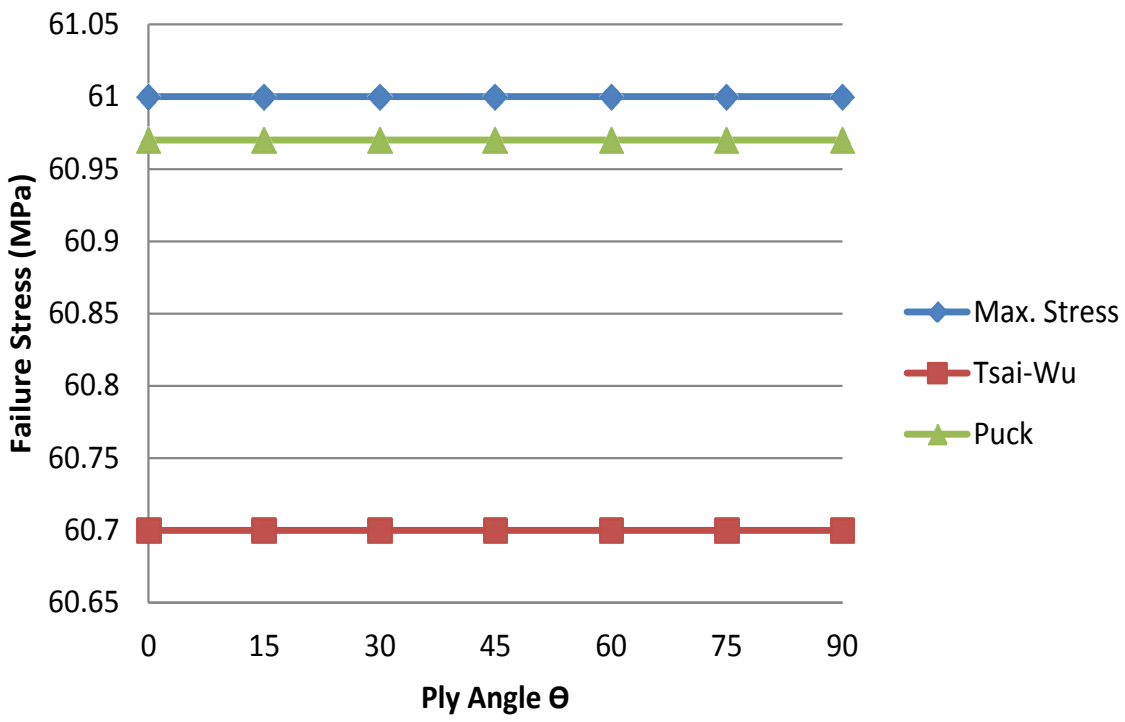

Figure 13: Variation of failure stress with ply angle $\theta$ for $\left(\theta^{\circ} / \theta \% \theta^{\circ} / \theta\right)$ laminate.

Case 2: $\left(\boldsymbol{\Theta}^{\circ} / 90^{\circ}-\mathbf{\Theta}^{\circ} / \mathbf{\Theta}^{\circ} / 90^{\circ}-\boldsymbol{\theta}^{\prime}\right)$ s: Shown in the Figure 11.

Case 3: $\left(\boldsymbol{\theta}^{\circ} /-\boldsymbol{\theta} \% \boldsymbol{\theta}^{\circ} /-\boldsymbol{\theta}\right)$ s: For $\left(\Theta^{\circ} /-\Theta \% \Theta^{\circ} /-\Theta\right)_{\text {s }}$ laminate scheme maximum failure strength occurs at $45^{\circ}$ ply angle. The obtained curve is symmetric about $45^{\circ}$ ply angle. Minimum failure strength is obtained when $\Theta$ is $0^{\circ}$ or $90^{\circ}$.

Case 4: $(\boldsymbol{\Theta} \% \boldsymbol{\Theta} \% \boldsymbol{\Theta})$ s: Shown in the Figure 13.

\section{Conclusions}

1. The Boron-Epoxy composition shows maximum strength and stiffness compare to Graphite-Epoxy and Aramid-Epoxy compositions for all fiber volume fractions.

2. Off axis failure strength of lamina decreases hyperbolically as off axis angle increases. The effect of fiber volume fraction is significant only up to $10^{\circ}$. Beyond $10^{\circ}$ failure strength is same for all volume fractions.

3. Under uniaxial loading condition $(\Theta \%-\Theta \% \Theta \%-\Theta)$ Laminate have higher failure strength than $\left(\theta \% \Theta \% \theta^{\circ} / \Theta\right)$ Laminates. Hence it is better to use angle ply instead of unidirectional plies under uniaxial loading conditions.

4. For biaxial loading conditions cross ply and angle ply laminates with ply angle $45^{\circ}$ exhibits highest failure strength than all other combinations.

\section{References}

1. Huang ZM (1999) Micromechanical strength formulae for unidirectional composites. Materials Letters. 40: 164-169 
Citation: Uniyal P, Gunwant D, Misra A (2016) Multi Scale Modeling and Failure Analysis of Laminated Composites. J Appl Mech Eng 5: 229. doi: 10.4172/2168-9873.1000229

Page 10 of 10

2. Tabiei A, Chen Q (2001) Micromechanics based composite material model for crashworthiness explicit finite element simulation. $\mathrm{J}$ of Thermoplastic Composite Materials.14: 264-288.

3. Reddy YSN, Reddy JN (1992) Linear and non-linear failure analysis of composite laminates with transverse shear. Composite Science and Technology. 44: 227-255

4. Kam TY, Sher HF, Chao TN (1996) Predictions of deflection and first-ply failure load of thin laminated composite plates via the finite element approach. Int $\mathrm{J}$ Solids Structure. 33: 375-398.

5. Rahimi N, Hussain AK (2012) Capability assessment of finite element software in predicting the last Ply failure of composite laminates. Int Symposium on Robotics and Intelligent Sensors 2012 (IRIS 2012) Procedia Engineering. 41 1647-1653.

6. Ramtekkar GS, Desai YM, Shah AH (2004) First ply failure of laminated composite plates - A mixed finite element approach. J of Reinforced Plastics and composites.

7. Pipes RB, Cole BW (1973) On the off axis strength test for anisotropic materials $\mathrm{J}$ of Composite Materials. 7: 246.

8. Kam TY, Sher HF, Chao TN (1996) Predictions of deflection and first-ply failure load of thin laminated composite plates via the finite element approach. Int $J$ Solids Structure 33: 375-398.

9. Joo SG, Hong CS (2000) Progressive failure analysis of composite laminates using 3-D finite element method key engineering materials. 183-187: 535-540.

10. Kaw AK (1997) Mechanics of composite materials. CRC Press New York: 149-184.

11. Kumar YVS, Srivastava A (2003) First ply failure analysis of laminated stiffened plates composite structures. 60: 307-315.

12. Liu PF, Zheng JY (2010) Recent development on damage modeling and finite element analysis for composite laminates: A review material and design. 31: 3825-3834.

13. Pal P, Bhattacharyya SK (2007) Progressive failure analysis of cross-ply laminated composite plates by finite element method. J Reinforced Plastic and Composites 26: 465-477.

14. Rahimi MA, Rahimi N, Hussain AK, Mahmud J, Musa M (2012) Parametric study on failure analysis of composite laminate under uniaxial tensile loading. IEEE Colloquium on Humanities Science and Engineering Research Sabah Malaysia.

15. Tolson S, Zabras N (1991) Finite element analysis of progressive failure in laminated composite plates composite \& structures 38: 361-376. 